\title{
Working Pattern and Mental Stress of Female Sex Worker
}

\author{
Authors \\ Dr Tonima Amir Haque ${ }^{1}$, Dr Ashekur Rahman Mullick², Dr Irin Hossain ${ }^{3 *}$ \\ ${ }^{1,3}$ National Institute of Preventive and Social Medicine, Dhaka, Bangladesh \\ ${ }^{2}$ Delta Medical College and Hospital, Dhaka, Bangladesh \\ *Corresponding Author \\ Dr Irin Hossain
}

\begin{abstract}
Sex work is a major public health problem worldwide. According to World Health Organization, sex work is the provision of sexual services for money or goods. Women engaging in sex work may be exposed to serious health risks and exposure to highly stressful life events which may have long term implications on their mental health. This cross-sectional study was done in drop-in center 'Swajan-33' in Sylhet district within a period of one year among 105 respondents aged of 14 to 38 years of age to assess the association between their working pattern and mental stress. Data were collected by face to face interview through a pretested structured questionnaire. Perceived Stress Scale was used to assess the level of mental stress. Data collected from purposively selected respondents. The analysis of data reveals that among 105 participants about $45.7 \%$ started sex work at the age of 16-20 years, 56.2\% of them did their job more than 3 days per week. Majority of the respondents $72.4 \%$ had customers less than 3 per day, Near about $49.5 \%$ choose this profession due to poverty, 59\% had interest to do any other job or work, $43.5 \%$ reported that loan was the main obstacles to leave this profession, $89 \%$ were using condom during sex work and $66.7 \%$ were using other birth control methods (injectable contraceptive). About $53.3 \%$ of the respondents had no definite place to go for this work. The finding of this study showed that $85.7 \%$ were suffering from high perceived stress and $14.3 \%$ were suffering from moderate stress. Develop and promote programs that offer viable alternatives for women who want to leave sex industry and help them to find a new job may help them to lead a prosperous life.
\end{abstract}

Keywords: Working pattern, Mental stress, Female sex worker.

\section{Introduction}

According to World Health Organization, sex work is the provision of sexual services for money or goods. Sex work appears to be fostered when there is a rise in demand for sexual services and a commendatory or favourable setting also coexist.

The circumstances in which it usually takes place includes a concentration of a sexually active population with sufficient anonymity and high ratio of males to females. Most importantly the socio- economic disparities that have sex work affordable by the client and an economic opportunity for the worker. These circumstances may be found in mining, industrial areas, ports, frontier market, towns communities along main transit line and transport routes. This work is also associated with travel and tourism, especially with the development of sex tourism. ${ }^{1}$

Sex work locations are those places or social networks in which sexual services are exchanged 
for cash or goods. There is an extensive range of diversity of sex work settings which can be ranging from well-established and visible brothel based, red light areas, looser collection of venues such as bars, hotels, marketplaces or roadside areas. There are considerable differences from one setting or location to the next in the way sex work organized. The stakeholders involved are also very diverse. They may include male, female or transgender sex workers, their clients and business owners, regular partners and third-party intermediaries, such as taxi drivers. ${ }^{1}$

Sex workers are a marginalized group in society due to the illegal nature if their work and stigma attached to their occupation. They also belong to vulnerable group of population as they are often exposed to high rates of violence from brothel owners, police and clients and they are exposed to health risks such as human immunodeficiency virus (HIV) infection and sexual harassment. Several studies have documented the high prevalence of violence among sex workers and its association with mental illness. The negative societal views of sex work and their psychological challenges force sex workers to conceal aspects of their identity and this leads to low self-esteem and self-worth. Many sex workers do not disclose their occupation to family, friends and close ones, which in turn leaves them socially isolated and lonely. These factors in turn predispose them to psychopath. Definite mental health disorders that are widespread in the sex worker population are anxiety disorders, posttraumatic stress disorder, mood disorders and substance abuse. $^{2}$

\section{Materials and Methods}

This cross-sectional study was done in drop-in center 'Swajan-33' in Sylhet district within a period of one year among 105 respondents aged of 14 to 38 years of age to assess the association between their pattern of work and mental stress.

\section{Selection Criteria}

Female sex workers were selected purposively by using the following inclusion criteria:

\section{Inclusion Criteria}

1) Female sex worker available at drop in center during data collection.

2) Willing to participate the study.

\section{Exclusion Criteria}

1) Severely ill or mentally unstable.

2) Who are not willing to participate.

\section{Sampling Technique}

As the target population was female sex workers so sex workers who willingly participated was included as a respondent, so the study demanded purposive sampling.

\section{Research Instruments}

All the information was collected by face to face interview through a semi-structured questionnaire to assess socio-demographic status and perceived stress scale was used to assess level of mental stress.

\section{Perceived Stress Scale Score}

PSS scores are obtained by reversing responses (e.g., $0=4,1=3,2=2,3=1 \& 4=0$ ) to the four positively stated items (items $4,5,7, \& 8$ ) and then summing across all scale items. A short 4 item scale can be made from questions 2, 4, 5 and 10 of the PSS 10 item scale.

Interpretation of Mental stress based on PSS scale:

1. 0-13 = Low stress.

2. $14-26=$ Moderate stress.

3. $27-40=$ High perceived stress.

\section{Results}

Among 105 participants about 45.7\% $(\mathrm{n}=48)$ started sex work at the age of $16-20$ years, $25.7 \%(n=27)$ started at $11-15$ years, $20 \%(n=21)$ started at $21-25$ years and $8.6 \%(n=9)$ at the age of 26-30 years. Mean age of initiation of sex work was 18.92 years (Figure 1). About 56.2\% ( $n=69)$ of the respondent did their job more than 3 days per week and about $43.8 \%(n=36)$ of the respondents did their job less than 3 days per week (Figure 2). About one third $39.3 \%$ of the adolescents $(n=11)$ used to work 4 days per week, $21.4 \%(n=6)$ work 3 days per week, $17.9 \%(\mathrm{n}=5)$ work 5 days per week, $10.7 \%(\mathrm{n}=3)$ work 6 days per week and $7.1 \%(n=2)$ work 7 days per week (Figure 3). Majority of the respondents $72.4 \%(n=76)$ had customers less than 3 per day and 
$27.6 \%(n=29)$ of the respondents had more than 3 customers in a day (Figure 4). About one third $32.1 \%$ of the respondents $(n=9)$ have average customers 2 per day, $28.6 \%$ have customers 3 per day, about a quarter $25 \%$ of the respondents $(n=7)$ have average 4 customers per day. $10.7 \%(\mathrm{n}=3)$ have 5 customers and $3.6 \%(n=1)$ have 6 customers on average per day (Figure 5). Near about half of the respondents $49.5 \%(\mathrm{n}=52)$ choose this profession due to poverty, $37.1 \% \quad(n=39)$ due to human trafficking, $6.7 \% \quad(n=7)$ each by willingly and forcefully (Figure 6). More than half 59\% $(n=62)$ respondents had interest to do any other job or work and $41 \%(n=43)$ had no interest to do any other work. Total 62 female sex workers answered about the obstacle to leave this profession and among them $43.5 \%(n=27)$ of the respondent reported that loan was the main obstacles to leave this profession, $29 \%(\mathrm{n}=18)$ reported it was family burden, and $19.4 \%$ $(n=12)$ reported due to personal cause they cannot leave this profession, and rest were due to their own society (Figure 7). Among the respondents most of them $89 \%$ were using condom during sex work and $11 \%$ were not using condom (Figure 8). Only 12 respondents answered about the cause of avoiding condom and among them $66.7 \%(n=8)$ were using other birth control methods (injectable contraceptive) and $33.3 \%(n=4)$ were reported that customer did not like to use condom (Figure 9). More than half $53.3 \%(n=56)$ of the respondents had no definite place to go for this work, $34.3 \%(n=26)$ of the respondents usually went in hotel, $11.4 \%(n=12)$ do this work in their own house and only $1 \%(n=1)$ went in brothel (Figure 10). Out of 105 respondents most of them $85.7 \%$ were suffering from high perceived mental stress and $14.3 \%$ were suffering from moderate stress (Figure 11). There was no significant relation in mental stress with starting sex work and duration of sex work.

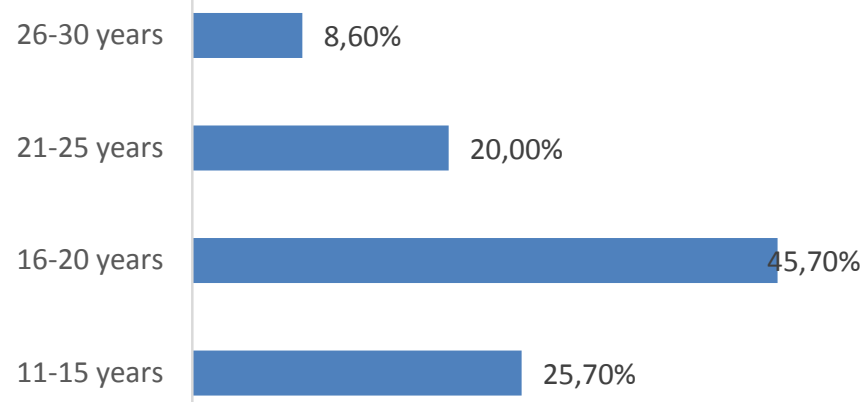

Figure 1: Age of starting sex work

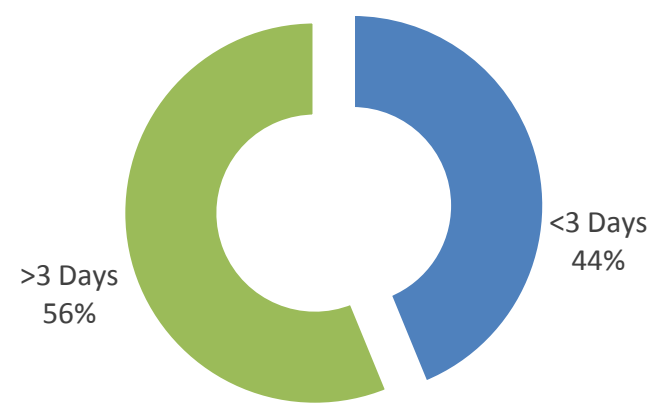

Figure 2: Weekly working days

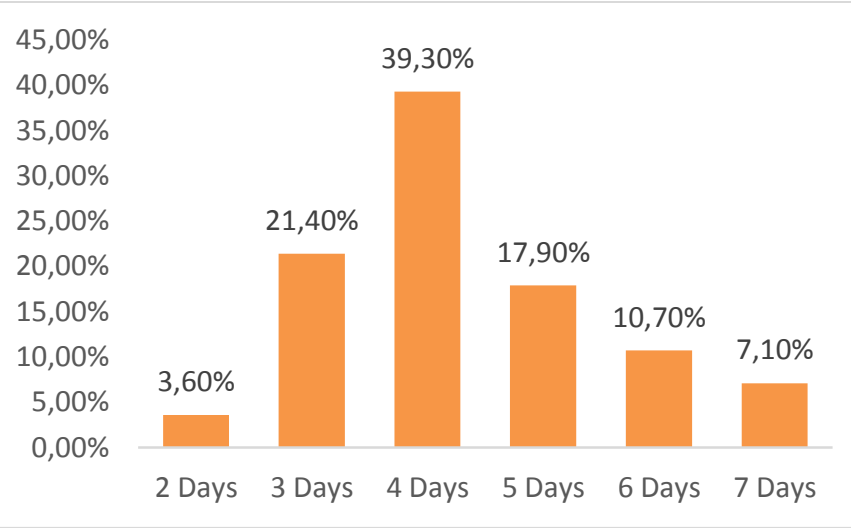

Figure 3: Weekly working days of the adolescents

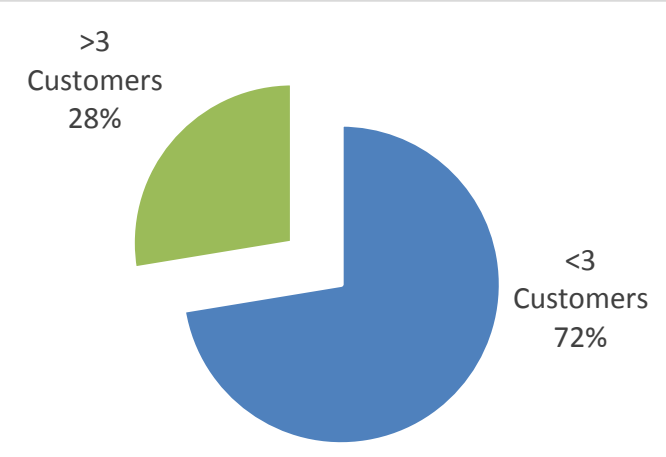

Figure 4: Average number of customer per day 


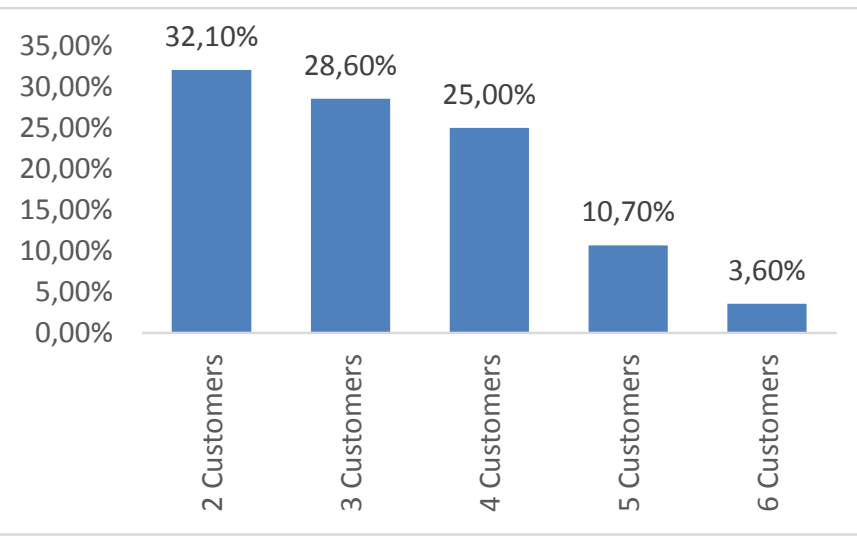

Figure 5: Average number of customer of the adolescents per day

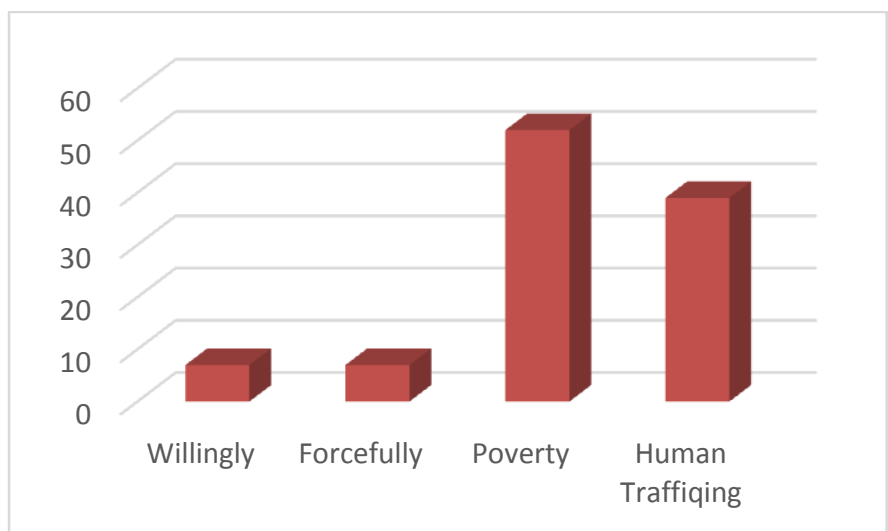

Figure 6: Reason to choose this profession

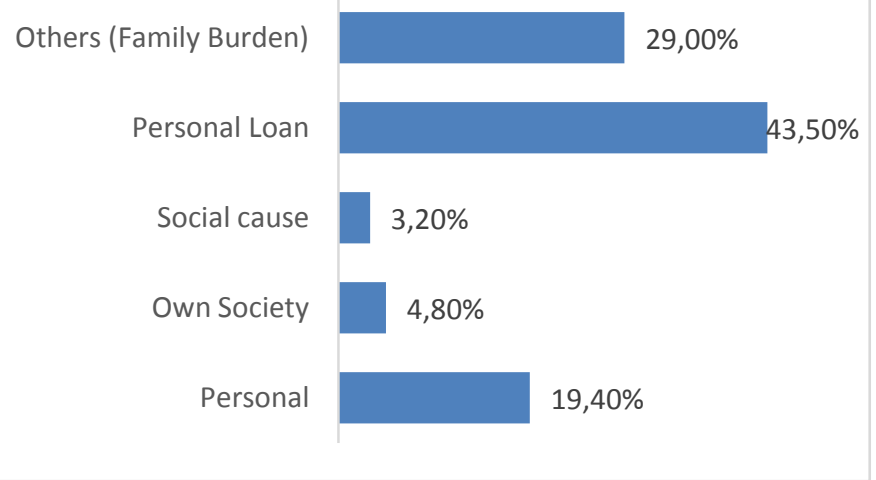

Figure 7: Obstacle to leave this profession

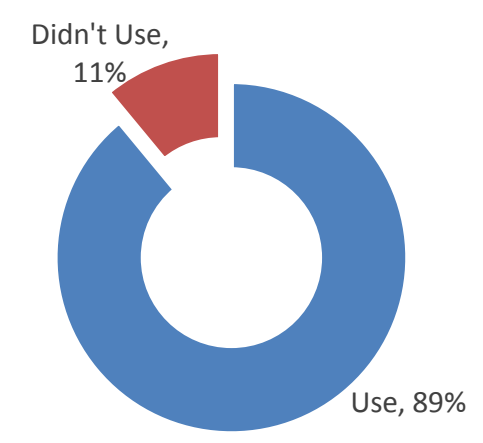

Figure 8: use of condom in each event

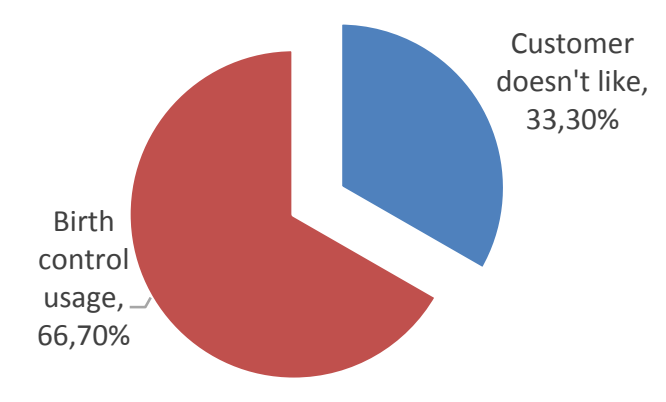

Figure 9: Reasons for avoiding condom

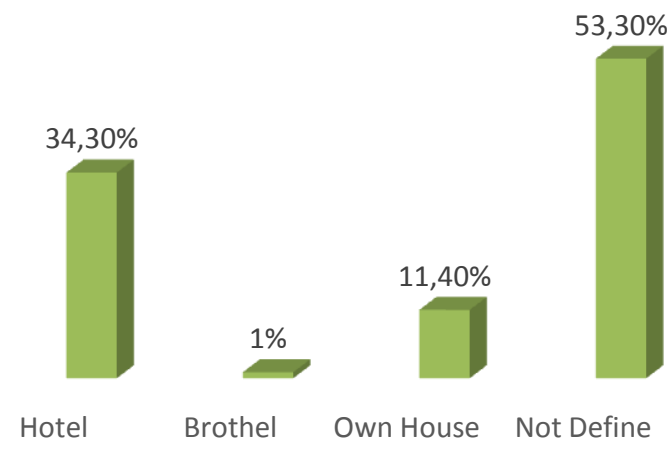

Figure 10: Place of sex work

- High perceived mental stress
- Moderate perceived mental stress

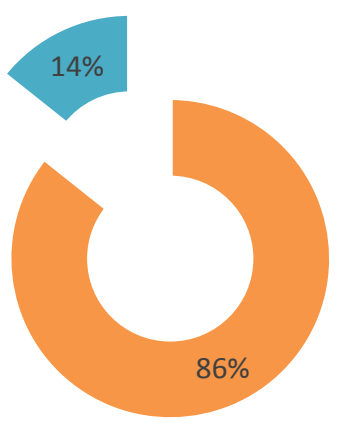

Figure 11: Level of Stress

\section{Discussions}

This study showed that the mean age of initiation sex work was 18.92 years. $45.7 \%$ female started at the age between 16 to years. $25.7 \%$ started between 11 to 15 years and $20 \%$ in between 21 to 25 years of age. A study in Dhaka among female sex workers shows the mean age at which these persons had begun their sex work was 18.5 years with some women starting as early as 10 years old. ${ }^{3}$ Another study in Korea of same population reported the 
initial age when they first engaged in prostitution ranged from 14 to 39 years. ${ }^{4}$ Regarding working days per week majority $56.2 \%$ respondents do their job more than 3 days per week and about $43.8 \%$ do their job less than 3 days per week. Among those respondents $27.6 \%$ have more than 3 customers per day and most of the respondents $72.4 \%$ have less than 3 customers in a day. A study in Zurich revealed that the interviewed women (fsw) worked on average more than 4 days per week. They serve on average 13 customers weekly basis. ${ }^{5}$ In this study about half of the respondents $49.5 \%$ choose this profession due to poverty.37.1\% due to human trafficking and $6.7 \%$ each by willingly and forcefully. Another study done in Chittagong among sex workers where in all, 224 women $86.5 \%$ expressed a desire to quit sex work. Among them $54.8 \%(n=142)$ came in this profession due to giving support to the family, $49.8 \%(n=128)$ due to forcefully and willingly $5.8 \% \quad(n=15)$. Several response options were possible. Social support was generally low, with only 58 women $22.4 \%$ indicated that they had a trusted person upon whom they could rely and $20.1 \%$ said they knew someone who was there to help when needed. ${ }^{3}$ This study showed that more than half of the respondents $59 \%$ had interest to do any other job and 41 percent had no interest to do any other work. Those had interest to do any other work loan is the main obstacle to leave this profession, 29\% cannot leave this profession due to have family burden, personal cause $19.4 \%$, due to their own society $4.8 \%$ and other social cause for which it is difficult for them to leave this profession is $3.2 \%$.Among the respondents most of the respondents $88.6 \%$ were using condom during sex work and remaining were not using condom. The reason for avoiding usage of condom were to use birth control which is $66.7 \%$ and one third $33.3 \%$ said customers does not like. In another study in Dhaka on sex workers which reported $65 \%$ hotel based workers and $52 \%$ street based workers used condoms during all sex acts with clients. ${ }^{6}$ Another study in Northwest Ethiopia the consistent and correct condom utilization among the female sex workers was $47.7 \% .{ }^{7}$ Regarding place of sex work almost half $53.3 \%$ of the respondents had no definite place to go for this work, $34.3 \%$ of the respondents usually went in hotel, $11.4 \%$ use their own house and only $1 \%$ went in brothel. In a study in Bangladesh showed only a minority worked in a brothel $8.1 \%$, most served $61.8 \%$ in their client's residence or $63.7 \%$ in residential hotels. ${ }^{3}$ Another study in Sydney, Australia reported three quarters of the women $75 \%$ providing services on the street and $67 \%$ reported providing them in cars. ${ }^{8}$ The finding of this study showed that among 105 respondents most of the female sex workers were suffering from high perceived stress $85.7 \%(\mathrm{n}=90)$ and only $14.3 \%(\mathrm{n}=15)$ were suffered from moderate stress. Another study in Queensland showed that $28 \%$ of the workers reported mild psychological distress and $58 \%$ depression. ${ }^{9}$ There was no significant relation in mental stress with starting sex work and duration of sex work.

\section{Conclusion}

In conclusion, this study explores that majority of the female sex workers are exposed to this profession within their age of twenty years, in which poverty is claimed to be the principle contributor. They are leading an insecure life with client, dwellers and law enforcing agents which may contribute to mental health disorder.

\section{Recommendations}

1) Develop and promote programs that offer viable alternatives for women who want to leave sex industry and help them to find a new job.

2) Prevention of human trafficking itself is needed, which can be advanced through the implementation of government policies.

3) This was an initial attempt to address the stress of female sex workers along with factors and their sex work pattern. Future research should be conducted on a large scale, taking in depth data from larger samples that can capture the scenario more clearly. 


\section{References}

1. Chudakov, B., Ilan, K., Belmaker, R.H. and Cwikel, J., 2002. The motivation and mental health of sex workers. Journal of Sex \& Marital Therapy, 28(4), pp.305-315.

2. Poliah, V. and Paruk, S., 2017. Depression, anxiety symptoms and substance use amongst sex workers attending a nongovernmental organisation in KwaZuluNatal, South Africa. South African Family Practice, 59(3), pp.116-122.

3. Hengartner, M.P., Islam, M.N., Haker, H. and Rössler, W., 2015. Mental health and Functioning of Female sex Workers in chittagong, Bangladesh. Frontiers in psychiatry, 6.

4. Jung, Y.E., Song, J.M., Chong, J., Seo, H.J. and Chae, J.H., 2008. Symptoms of posttraumatic stress disorder and mental health in women who escaped prostitution and helping activists in shelters. Yonsei medical journal, 49(3), pp.372-382.

5. Rössler, W., Koch, U., Lauber, C., Hass, A.K., Altwegg, M., Ajdacic- Gross, V. and Landolt, K., 2010. The mental health of female sex workers. Acta Psychiatrica Scandinavica, 122(2), pp.143-152.

6. Katz, K.R., McDowell, M., Green, M., Jahan, S., Johnson, L. and Chen, M., 2015.Understanding the broader sexual and reproductive health needs of female sex workers in Dhaka, Bangladesh. International perspectives on sexual and reproductive health, 41(4), pp.182-190.

7. Tamene, M.M., Tessema, G.A. and Beyera, G.K., 2015. Condom utilization and sexual behavior of female sex workers in Northwest Ethiopia: A cross-sectional study. Pan African Medical Journal, 21(1).

8. Roxburgh, A., Degenhardt, L. and Copeland, J., 2006. Posttraumatic stress disorder among female street-based sex workers in the greater Sydney area, Australia. BMC psychiatry, 6(1), p.24.
9. Boyle, F.M., Dunne, M.P., Najman, J.M., Western, J.S., Turrell, G., Wood, C. and Glennon, S., 1997. Psychological distress among female sex workers. Australian and New Zealand journal of public health, 21(6), pp.643-646. 